\title{
The Relationship Between Academic Success and Emotional Intelligence, Psychological Empowerment, Resilience, Spiritual Well-Being in Nursing Students
}

\author{
Rukhsana Taj $^{1 *} \quad$ Muhammad Hussain $^{2} \quad$ Muhammad Afzal $^{3} \quad$ Syed Amir Gilani ${ }^{4}$ \\ Lahore School of Nursing, The University of Lahore
}

\begin{abstract}
Background: The academic achievement of nursing students plays an important part in the professional development. It is essential and compulsory element in their professional development stages. There are multiple factors that affect students' academic achievement like emotional intelligence, spiritual well being, psychological empowerment, and resilience. These factors can effect positively or negatively to academic success in terms of CGPA.

Method: a descriptive co relational study design used in this study. The study conducted in The University of Lahore on 117 students of Nursing. The sample size calculated through Solvens formula. For questionnaire is used in this study Emotional intelligence scale, Psychological empowerment scale, resilience scale and spiritual well being test.

Results: results are showing positive correlation in dependent and independent variables. There is significant correlation in spiritual well being and CGPA( $(\mathrm{r}=.75, \mathrm{p}=.003)$. There is positive correlation between psychological empowerment and CGPA $(\mathrm{P}=.773, \mathrm{r}=.000)$. There is correlation between resilience and CGPA $(\mathrm{r}=.731, \mathrm{p}=.000)$. There is positive correlation between Emotional intelligence and CGPA $(\mathrm{P}=.766, \mathrm{r}=.000)$ at the level of 0.05 .

Conclusion: all the universities and institutes must be makes and implementing some strategies for the reduction of bias selection of students. For the improving of nursing students, academic performance there is a need to implement some intervention for the reduction and coping with stress (resilience), and provide such environment that is free from stress.
\end{abstract}

Keywords: Relationship, Academic Success, Emotional Intelligence, Spiritual well being, Resilience, Psychological Empowerment

DOI: $10.7176 / \mathrm{JHMN} / 62-10$

Publication date:May $31^{\text {st }} 2019$

\section{Introduction}

Background: Academic achievement of nursing students plays an important part in the professional development. It is essential and compulsory element in their professional development stages. There are multiple factors that affect students' academic achievement like emotional intelligence, spiritual well being, psychological empowerment, and resilience. These factors can effect positively or negatively to academic success in terms of CGPA.

Psychological empowerment is a state, which is important for a person that how the person perceive the feeling of control in connection to their work. It mirrors an alliance of four employment related cognition, which are meaning, competence, self-determination, and impact. Meaning suggests the dimension of fit between work necessities and one's characteristics, norms and beliefs. Competence is oneself assessed faith that one has the capacities to play out one's employment adequately and is firmly identifies with self-viability. Self- determination includes having a feeling of control in the induction and management of one's activities. Impact is the belief that one can have important influence on good outcomes (Spreitzer. 2008 as cited by Morin et al., 2016).

Resilience is individuals' capacity to get a hold of themselves before troublesome life experiences or their capacity to adapt to emergencies or calamities effectively. It is especially vital for nurses to boost their resilience since they face numerous traumatic circumstances in their disturbing experienced lives (Cam \& Buyukbyram, 2015).

Resilience is important in the academic carrier of nursing students and organizes by nurses' education. As describes in the examinations, nursing understudies and nursing faculty experience important hardships that needed them to have resilience. For instance, resilience was exhibited through students 'perseverance with their difficulties, which at that point is a contributing element in encouraging achievement in their nursing instruction and in the achievement of their degrees (Carrol., 2011 as cited by Reyes, Andrusyszyn, Iwasiw, Forchuk, \& Babenko-Mould, 2015).

Five important components of resilience are Equanimity, Self-reliance, Perseverance, Meaningfulness, and existential aloneness. Equanimity introduce as a reasonable viewpoint of life and encounters and may be seen as sitting free and taking what comes, along these lines directing the extreme reactions to misfortune, a develop frequently identified with the sensibility of playfulness. 
Perseverance is the capacity to prop up regardless of misfortunes, largely found in individuals who will in general perceive and depend on their own qualities and abilities. Self-reliance is views as a self-viability belief extraordinarily connected to critical thinking abilities. This capacity is accomplish with life encounters and is often as possible experience in individuals who grasps and acknowledges their very own abilities and limitations. Meaningfulness is the faith that life has a reason also, acknowledgment that there is an explanation behind which to live. Existential aloneness is the acknowledgment that every individual is one of a kind and that although a few experiences can be shared, others must be fight alone (Damásio, Borsa, \& da Silva, 2011).

Spiritual Well Being Scale is a general marker of seen well-being, which might be utilize, for the evaluation of both individual and congregational SWB. It gives a general proportion of a person's impression of the otherworldly quality inside their lives and comprises of two sub-scale religious well-being and existential wellbeing. The religious prosperity sub-scale gives a self-evaluation of one's association with God, while the existential well-being sub-scale offers a self-evaluation of one is feeling of life reason and life fulfillment. Spiritual wellbeing is characterizing as a complicated build enveloping existential what's more, religious measurements. Existential well-being identifies with a person's undertaking to comprehend the importance and motivation behind life, while religious well-being indicate to the fulfillment picked up from a confidence in an unrivaled power, for example, God. As it were, Spiritual well-being characterized to the powerful experience of positive sentiments that outcome from one's capacity to encounter importance and reason in life through his or her association with oneself, others, and a higher power. Spiritual well-being has in this manner been characterized as the attestation of life involved with oneself (individual), others (shared), nature (condition), and God (Hungelmann et al. 1996 as cited by Soleimani et al., 2017).

Emotional intelligence is an idea that enables people to comprehend and deal with their very own feelings and those of others, relating, inspiration and improving self-assurance. Self-awareness is a people's mindfulness of their feelings, their results and articulation. It isn't just about monitoring feelings, yet additionally understanding their causes and the contrasts between them (Cam \& Buyukbayram, 2015).

\subsection{Problem Statement}

In the students, there is most of seen that the academic achievement of the student is low. Many factors are affecting the academic performance of students. The student's cognition about their studies, how to perceive their studies and the impact of these factors on their results is including in psychological empowerment and the psychological empowerments are biggest factor that is effecting on students academic performance. If there is no development of psychological empowerment automatically, CGPA of students will be low. The other factor that can be effect on student's academic success is resilience (Carrol., 2011 as cited by Reyes et al., 2015).

The Coping power of the students, that how much a student is flexible in the coping of stressful environment. If the student is unable to cope with stress of study, they cannot maintain their academic performance to enhance their CGPA. The spirituality of the students will also affect their academic performance. Their faith on Allah Almighty is the highest factor of their satisfaction of mind. If the spirituality of student will be strong about ALLAH, they will be mentally satisfied and academic performance will be high. The emotional intelligence of the student is effecting on academic success. If the student will emotional strong, they will perceive well about their study, if they think positive about their studies, they handle their emotions in positive, and good way in studies the academic performance will be enhance. In addition, these all factors can lead the high academic performance and good CGPA. If the psychological empowerment, emotional intelligence, resilience and spiritual well-being of the students are not positive, the academic performance and CGPA of student will be low

\section{PURPOSE OF THE STUDY}

The purpose of the study is to see the relationship between academic success and emotional intelligence, psychological empowerment, resilience, spiritual well being in nursing students.

\section{Literature review}

A co relational study shows there is a significance relationship between the psychological empowerment, resilience, spiritual well-being and academic success in this study supports the statements in the literature that these ideas may assume a significant job in diligence through the difficulties of nursing instruction. There is a Need to done to advance nursing understudies achievement. Little has been composed on tending to non psychological or psychosocial factors that advance scholarly achievement, other than recommending mediations, for example, alluding understudies for directing What's more, for stress discharge(Beauvais, Stewart, DeNisco, \& Beauvais, 2014).

A study shows Connections between emotional intelligence and increased nursing performance levels has accounted for with accentuation on the significance of developing a minding and aware condition that bolsters successful correspondence and solid relational relationship associations. At the point when nurses benefit from EI skills with individual and relational capacities to deal with quickly changing customer care circumstances, are 
quiet despite disappointment, and can build up a situation that is both empathetic and recuperating, generally speaking patient consideration improves (Reemts, 2015).

According to a study, Resilience is significant in the activity of nursing understudies and nursing faculty. Resilience is important in the academic carrier of nursing understudies and organizes by nurses' education. As describes in the examinations, nursing understudies and nursing faculty experience important hardships that needed them to have resilience. For instance, resilience was exhibited through students 'perseverance with their difficulties, which at that point was a contributing element in encouraging achievement in their nursing instruction and in the achievement of their degrees (Reyes et al., 2015).

A study was conducting to find out a relationship between emotional intelligence and spiritual well-being. According to sit there is a significance relationship between both variables. Emotional intelligence may upgrade spiritual improvement and instruction as feelings are a premise of mindfulness and commitment inside humankind (Beauvais, Stewart, \& DeNisco, 2014).

Results of a study shows aptitudes that manage how effectively individuals perceive and express their feelings, remember others emotions and relate with them, and handle with day by day stresses or weights, successfully emotional intelligence is fundamentally identified with better academic accomplishment among understudies (Hanafi \& Noor, 2016).

\section{Research objectives}

Find out the significance relationship between the academic success and spiritual well-being, emotional intelligence, psychological empowerment, and resilience in nursing students?

\section{Significance of the study}

The significance of this study lies on various points. The first point is, the consequences of this study might be utilized as a way to estimated factors that most adequately anticipate student's academic achievement.

There is a need for nurses and student nurses to know about their very own spiritual beliefs and have some feeling of other worldly prosperity. Spiritual well-being includes, getting and cultivating instructed about other worldliness and may advance their spiritual prosperity. Numerous of the training techniques noted in the writing include an emotional part, for example, teachers are good examples for understudies.

Based on this research the organization can conduct seminars and workshops for the teachers, because teachers are the role model for students.

After the research findings, researcher will address the knowledge to the clinical teachers that there is a significance relationship between academic success \& emotional intelligence, psychological empowerment, resilience and spiritual well-being to the higher authority.

\section{Material \& Methodology:}

This chapter consists of study design, sample size, study setting, instrument, target population, sampling method, sampling technique, inclusion criteria, exclusion criteria, data collection, analysis of data, and ethical consideration.

\section{Study design}

A Descriptive co- relational study design was used. Quantitative study design was used in this study in which; dependent variable is academic success, that is measure by CGPA of the nursing students, and spiritual well-being scale, emotional intelligence scale, psychological empowerment scale and resilience scale are independent variables. This dependent and independent variables have a significance correlation between each other. For the finding of this relationship a descriptive co-relational study design was used.

\section{Study Setting}

This study was conducted in Lahore School of Nursing, The University of Lahore.

\section{Study site}

The sample was collecting from the nursing students of Bachelor of Science in Nursing (generic), and Post R.N from Lahore school of nursing, The University of Lahore. Semester two, semester five and semester seven from Bachelor of Science in Nursing (generic), and semester two and semester four from Bachelor of Science in Nursing (Post R.N).

\section{Target population}

The target population was from Bachelor of Science in Nursing (BSN), Post R.N

\section{Sample technique}

Sample for this research was collected through convenient sampling technique. Convenient sampling technique is 
a non probability sampling techniques for selecting the convenience and accessible sample.

\section{Sample size:}

The sample size will calculated through Solvens formula (1960)

$\mathrm{n}=\mathrm{N} / 1+\mathrm{N}(\mathrm{e}) 2$

$\mathrm{n}=166 / 1+166(0.005) 2$

$\mathrm{n}=166 / 1+0.415$

$\mathrm{n}=166 / 1.415$

$\mathrm{n}=117$

\section{Inclusion criteria:}

Inclusion criteria of present study involve; All male and female Senior and junior nursing students. With the age group of 18 Years to 57 Years. From Bachelor of Science in Nursing (Generic) From Bachelor of Science in Nursing (Post RN) students, Those students who passed semester one. Those students who were willingly participate in this study.

Exclusion criteria: Exclusion criteria of study involve;

Students less than 18 Years of age and above the 57 Years of age, Less clinical experience, and Those students who were not participate willingly.

Study instruments

Spiritual well-being scale: This scale is contains 20 items six -point rating scale ranging from strongly disagree to strongly agree, this tool is for assessing overall spirituality. Reliability of this tool is checked and value is .756 (Cronbach's Alpha) that is very satisfactory.

Emotional intelligence scale: Emotional Intelligence scale contains 33 items five- point rating scale. Reliability of this tool is .978 (Cronbach's Alpha) which is good and realizable.

Psychological empowerment scale : This scale contains 12 items seven- point rating scale. This scale was developed by Sprietzer's for measuring the psychological empowerment. Reliability was checked by Cronbach's Alpha test and value is .790, which shows this instrument is reliable.

Resilience scale: This tool was contains 14 items rating scale. This scale was developed by Wagnild and Young in 1993.value of Cronbach's Alpha is .800 that is reliable.

Data collection

Approval of this study will be taken from the head of the department of Lahore school of nursing, the university of Lahore and data will collected by using structured questionnaires.

\section{Study Duration}

Duration of this present study is from Jan 29, 2019 to $2^{\text {nd }}$ May, 2019.

\section{RESULTS}

This chapter is consisting of four sections. Section 1 is demographic of the participants, section 2 is reliability and validity analysis of the variables, section 3 is frequency distribution of the variables, and section four is correlation of the variables. Total participants of the study are the 117 including all senior junior students of Lahore school of Nursing. This study is conducts to see the significance relationship between academic success and emotional intelligence, psychological empowerment, resilience, spiritual well-being in nursing students. 


\section{Section: 1}

Table: 1

Demographic of the participants

\begin{tabular}{|c|c|c|c|}
\hline \multicolumn{2}{|c|}{$\begin{array}{c}\text { Characteristics } \\
\end{array}$} & Frequency & Percentage \\
\hline \multirow[t]{2}{*}{ Gender } & Male & 16 & 13.7 \\
\hline & Female & 101 & 86.3 \\
\hline \multirow[t]{2}{*}{ Status } & Married & 09 & 7.7 \\
\hline & Unmarried & 108 & 92.3 \\
\hline \multirow[t]{3}{*}{ Age } & $18-27$ & 92 & 78.6 \\
\hline & $28-37$ & 19 & 16.2 \\
\hline & $38-47$ & 6 & 5.1 \\
\hline \multirow[t]{4}{*}{ Year } & $1^{\text {st }}$ year & 9 & 7.7 \\
\hline & $2^{\text {nd }}$ year & 61 & 52.1 \\
\hline & $3^{\text {rd }}$ year & 35 & 29.9 \\
\hline & $4^{\text {th }}$ year & 12 & 10.3 \\
\hline \multirow[t]{3}{*}{ Program } & Undergraduate junior & 17 & 14.5 \\
\hline & Undergraduate senior & 57 & 48.7 \\
\hline & BSN( Post RN ) & 43 & 36.8 \\
\hline \multirow[t]{4}{*}{ CGPA } & $2-2.5$ & 08 & 6.8 \\
\hline & $2.5-3$ & 15 & 12.8 \\
\hline & $3-3.5$ & 40 & 34.2 \\
\hline & $3.5-4$ & 54 & 46.2 \\
\hline
\end{tabular}

The gender of student is including 16(13.7\%) male and 101(86.3\%) female. The marital status of student $9(7.7 \%)$ are married and $108(92.3 \%)$ are unmarried. The age of the students are including $92(78.6 \%)$ from $18-27$ years, $19(16.2 \%)$ from $28-37$ year, and $6(5.1 \%)$ from $38-47$ years. The class of the students is including $9(7.7 \%)$ from $1^{\text {st }}$ year, $61(52.1 \%)$ from $2^{\text {nd }}$ year, $35(29.9 \%)$ from $3^{\text {rd }}$ year and $12(10.3 \%)$ from $4^{\text {th }}$ year. The $17(14.5 \%)$ students are undergraduate junior, 57(48.7\%) students are undergraduate senior and $43(36.8 \%)$ students are from BSN Post RN. The CGPA of $8(6.8 \%)$ students is in the range of 2-2.5, CGPA of $15(12.8 \%)$ students is in the range of 2.5-3, and CGPA of 40 (34.2\%) students is in the range of 3-3.5, and CGPA of 54(46.2) students in the range of 3.5-4. CGPA

Correlation between spiritual well-being, psychological empowerment, resilience, emotional intelligence and

\begin{tabular}{|c|c|c|c|c|c|c|}
\hline \multicolumn{7}{|c|}{$\begin{array}{c}\text { Correlations } \\
\end{array}$} \\
\hline & & $\begin{array}{l}\text { spiritual well } \\
\text { being }\end{array}$ & $\begin{array}{l}\text { Psychological } \\
\text { empowerment }\end{array}$ & resilience & $\begin{array}{l}\text { emotional } \\
\text { intelligence }\end{array}$ & CGPA \\
\hline \multirow[t]{3}{*}{ spiritual well being } & $\begin{array}{l}\text { Pearson } \\
\text { Correlation }\end{array}$ & 1 & $.326^{* *}$ & $.227^{*}$ & $.230^{*}$ & $.275^{* *}$ \\
\hline & Sig. (2-tailed) & & .000 & .014 & .013 & .003 \\
\hline & $\mathrm{N}$ & 117 & 117 & 117 & 116 & 117 \\
\hline \multirow[t]{3}{*}{$\begin{array}{l}\text { Psychological } \\
\text { empowerment }\end{array}$} & $\begin{array}{l}\text { Pearson } \\
\text { Correlation }\end{array}$ & $.326^{* *}$ & 1 & $.853^{* *}$ & $.854^{* *}$ & $.773^{* *}$ \\
\hline & Sig. (2-tailed) & .000 & & .000 & .000 & .000 \\
\hline & $\mathrm{N}$ & 117 & 117 & 117 & 116 & 117 \\
\hline \multirow[t]{3}{*}{ Resilience } & $\begin{array}{l}\text { Pearson } \\
\text { Correlation }\end{array}$ & $.227^{*}$ & $.853^{* *}$ & 1 & $.773^{* *}$ & $.731^{* *}$ \\
\hline & Sig. (2-tailed) & .014 & .000 & & .000 & .000 \\
\hline & $\mathrm{N}$ & 117 & 117 & 117 & 116 & 117 \\
\hline \multirow[t]{3}{*}{$\begin{array}{l}\text { emotional } \\
\text { intelligence }\end{array}$} & $\begin{array}{l}\text { Pearson } \\
\text { Correlation }\end{array}$ & $.230^{*}$ & $.854^{* *}$ & $.773^{* *}$ & 1 & $.766^{* *}$ \\
\hline & Sig. (2-tailed) & .013 & .000 & .000 & & .000 \\
\hline & $\mathrm{N}$ & 116 & 116 & 116 & 116 & 116 \\
\hline \multirow[t]{3}{*}{ CGPA } & $\begin{array}{l}\text { Pearson } \\
\text { Correlation }\end{array}$ & $.275^{* *}$ & $.773^{* *}$ & $.731^{* *}$ & $.766^{* *}$ & 1 \\
\hline & Sig. (2-tailed) & .003 & .000 & .000 & .000 & \\
\hline & $\mathrm{N}$ & 117 & 117 & 117 & 116 & 117 \\
\hline
\end{tabular}

**. Correlation is significant at the 0.01 level (2-tailed).

*. Correlation is significant at the 0.05 level (2-tailed). 
Results showing that there is significant correlation in spiritual well being and CGPA(r=.75, $\mathrm{p}=.003)$. There is positive correlation between psychological empowerment and CGPA $(\mathrm{P}=.773, \mathrm{r}=.000)$. There is correlation between resilience and CGPA $(\mathrm{r}=.731, \mathrm{p}=.000)$. There is positive correlation between Emotional intelligence and CGPA $(\mathrm{P}=.766, \mathrm{r}=.000)$ at the level of 0.05 .

\section{Discussion}

The results of this present study shows that the relationship between the academic success and relationship between academic success and emotional intelligence, psychological empowerment, Resilience, spiritual well-being in Nursing Students. Academic success was measured with the students accumulative grade point score (CGPA), greater GPA shows good performance in acadenics.mean score of the CGPA was 3.20. Schutte Self-Report Emotional Intelligence Test was used for the measuring of the Emotional intelligence of the students. Mean score of Emotional intelligence was 3.74, $\mathrm{SD} \pm 0.98$. it shows a good relationship between the academic success and emotional intelligence. Psychological empowerment was measure through psychological empowerment scale. Mean score was 4.84 and $\mathrm{SD} \pm 1.38$. that was indicated that there is a significance relationship between the variables. Resilience measured by using the Wagnild and Young 14 items resilience scale. Mean score was 5.15 and SD \pm 1.35 .it shows positive relationship in both academic success and resilience. Spiritual well-being scale was use for measuring the Relation between academic success and spiritual well-being. Mean score of spiritual well-being was 3.94 and $\mathrm{SD} \pm 0.64$.this higher score indicates that there is a significant relationship between academic success and spiritual well-being. The current study found that resilience was higher relates to academic success in nursing students. The results support that persons with high resilience shows better academic performance and success. Spiritual well-being was relates to academic success in both groups of students by themselves, but was significant when the overall sample was considered. Overall results of this study indicate that there is a significant co-relation between academic success and emotional intelligence, psychological empowerment, Resilience, spiritual wellbeing in Nursing Students.

\section{Limitation}

Due to the convenient sample technique and the relatively small sample size, the participants of this study may not be represents the all-nursing students. Thus, the results of this study shell not be guardedly concluded. Moreover, the study was conduct in such university that is not offering all nursing program. Another limitation is selfreporting which can be responsive for the further learning. In this research, self-report was apply in the spiritual well-being, resilience, and psychological empowerment scale as well as with the self-reported GPA scores.

\section{Conclusion}

Conclusion is that, all the universities and institutes must be makes and implementing some strategies for the reduction of bias selection of students. For the improving of nursing students, academic performance there is a need to implement some intervention for the reduction and coping with stress (resilience), and provide such environment that is free from stress. Addressing some others, psychological and non-cognitive factors that are helpful for improvement of academic achievement or success are psychological empowerment, emotional intelligence, resilience and spiritual well-being. There is a need to improve teaching/learning strategies and developing curricula according to related factors.

\section{Acknowledgement}

I want to express my appreciation to these persons for their assistance to this thesis in respective way. First of all I am very thankful to ALLAH Almighty, who is the most beneficial and merciful and Prophet MUHAMMAD (SAW), who through His charity has given the bravery and strength of mind to complete this project. I want to pay a bundle of thanks of my supervisory team headed by Sir MUHAMMAD AFZAL, co-supervisor Sir MUHAMMAD HUSSAIN for giving me opportunity to complete this thesis, and always helping me when I have a question related to my research work. I would like to pay thank my family, specially my parents who always pray for my study. I would like to pay special thanks to Deputy Nursing superintendent Madam BUSHRA HUSSAIN from surgical tower Mayo Hospital Lahore who support me for completing my study. I would like to pay thank to All Nursing students from the university of Lahore, who provide me data for this study and made this study possible.

\section{Dedication}

To my Husband: NAVEED BHATTI

The study is dedicated to my beloved husband who supports me in every aspect of life; he wants me to be a successful and finically support me, .He is always encouraging me for study and wants to see successful. 


\section{References}

Astin, A. W. (2012). Assessment for excellence: The philosophy and practice of assessment and evaluation in higher education: Rowman \& Littlefield Publishers.

Beauvais, A. M., Stewart, J. G., \& DeNisco, S. (2014). Emotional intelligence and spiritual well-being: implications for spiritual care. Journal of Christian Nursing, 31(3), 166-171.

Beauvais, A. M., Stewart, J. G., DeNisco, S., \& Beauvais, J. E. (2014). Factors related to academic success among nursing students: A descriptive correlational research study. Nurse Education Today, 34(6), 918-923.

Cam, O., \& BÜYÜKBAYRAM, A. (2015). The Results of Nurses' Increasing Emotional Intelligence and Resilience. Journal of Psychiatric Nursing/Psikiyatri Hemsireleri Dernegi, 6(3).

Damásio, B. F., Borsa, J. C., \& da Silva, J. P. (2011). 14-item resilience scale (RS-14): psychometric properties of the Brazilian version. Journal of nursing measurement, 19(3), 131-145.

Hanafi, Z., \& Noor, F. (2016). Relationship between emotional intelligence and academic achievement in emerging adults: A systematic review. International Journal of Academic Research in Business and Social Sciences, 6(6), 268-290.

Reemts, G. S. (2015). Emotional intelligence levels in baccalaureate-prepared early career registered nurses. AsiaPacific journal of oncology nursing, 2(2), 72.

Reyes, A. T., Andrusyszyn, M. A., Iwasiw, C., Forchuk, C., \& Babenko-Mould, Y. (2015). Resilience in nursing education: An integrative review. Journal of nursing education, 54(8), 438-444.

Soleimani, M. A., Sharif, S. P., Allen, K. A., Yaghoobzadeh, A., Nia, H. S., \& Gorgulu, O. (2017). Psychometric properties of the persian version of spiritual well-being scale in patients with acute myocardial infarction. Journal of religion and health, 56(6), 1981-1997. 